\title{
Representation of Digital Native Generation in Visual Images
}

\author{
Rizki Taufik Rakhman $^{1^{*}} \quad$ Yasraf Amir Piliang $^{1} \quad$ Hafiz Aziz Ahmad $^{1} \quad$ Iwan Gunawan $^{2}$ \\ 1.Faculty of Fine Art and Design, Bandung Institute of Technology (ITB), Ganesha 10, Bandung, Indonesia \\ 40132 \\ 2.Faculty of Fine Art, Jakarta Art Institute (IKJ), Cikini 73, Jakarta, Indonesia 10330
}

\begin{abstract}
Digital Native is a term given to generations who are born, grow and develop in line with digital technology. In general, the term is given to generation $Z$ whose birth span is between 1995-2010, where the development of digital technology was on the rise. This has had an impact on the character of Generation $Z$ itself. One of the characters that appears is self-existence. They do not hesitate to present themselves to the general public, especially on social media. The problem addressed in this research is excessive self-existence without consideration that content may bring adverse image into the generation itself. Through this research, it is hoped that the digital native generation will be able express themselves through visual images to show what their characters really want to be known and recognized as. Rather than following trends that sometimes trap them in uniformity which results in dull creativity preventing them to be themselves. The method uses in this research is the experimental method, whereby several experimental groups are created consisting of individuals from among the digital native generation with various backgrounds. Experiments in the form of visual images that represent themselves. The experiment's results will then be analyzed by using visual language and produce representative categories of digital native generation.
\end{abstract}

Keywords: digital native generation, representation, visual images

DOI: $10.7176 / \mathrm{ADS} / 90-03$

Publication date: February $28^{\text {th }} 2021$

\section{Introduction}

According to Stillman \& Stillman, digital native generation is a term intended to label generation Z. The term refers to the period during which generation $Z$ were born, namely between 1995-2010 when technological development progressed rapidly and often referred to as the digital era. Every generation poses a character that represents its era, and the digital native generation is no exception.

The characteristics of the digital native generation includes high value on freedom, short attention span, desire to express themselves, tendency to think fast but not deeply, learning by seeking instead of following instructions, downloading and uploading, social interaction on social media, penchant to sharing and collaborating. From the above eight characteristics of the digital native generation, the researcher is interested in testing one of the most dominant characters, namely self-existence; freedom of expression towards selfactualization.

The researcher's attention is focused on the digital native generation's character wanting recognition from society. Existence on social media is daily food for the digital native generation. But what about conventional media with which they are less familiar? Is their existence able to be manifested only through social and digital media? Or could conventional media through visual images of the digital native generation can also serve as a platform for them to express themselves just like social media?

In Indonesia, there have been many cases of digital native generation that relate to their existence on social media. In general, these various cases include this generation's unreserved readiness to follow current trends. It is as if they compete to be followers of a social media trends without giving serious thought on the impact of such action.

This research aims to restore the digital native generation's capacity for imagination and creativity through visual images thus allowing them to be free to express their ideas which would ultimately become the representation of their generation.

\section{Methods}

The research method used in this research is the experimental research method. Two types of experimental research are used in this exercise, namely: Pre-experimental and True Experimental methods. The PreExperimental method was chosen in conducting a preliminary study before implementing the True Experimental method. While the True Experimental method component will consist of Variable Manipulation, Control, Random Assignment, and Treatment. The research design in the pre-experiment phases is the single group design with pre-tests and post-tests. While the research design in the True Experiment phase is a Pre-test-Posttest Design using a Control Group with Random Assignments.

The data collection method employed in this study involved documents and observations. Documents 
include folktale books, photos, activity schedules and analog media that were created by the research team. These tools are expected to provide descriptive information that is very helpful for the research team in analyzing the data. With these qualitative documents, the data analysis will be more in-depth according to the research needs. In addition, the research team also carried out observations, which activity did not only comprise of taking notes, but also making considerations that are set forth in a multilevel scale. The type of observation chosen to be conducted was non-participatory observation, where the research team do not interact with the study subjects. The research team merely acted as an observer.

\section{Result of Experiment}

The purpose of the experiment is to find out by identifying the characters that represent each member of the experimental groups. The researchers and the team have formulated scenarios in which tasks are to assign to create narratives and visual images of a character that represents the subjects. Each member of the experimental group is accompanied by a research team whose task is to help group members explore ideas, and develop character and motivate members during the research activities so that imagination and creativity can be optimally visible in their resultant visual images work.
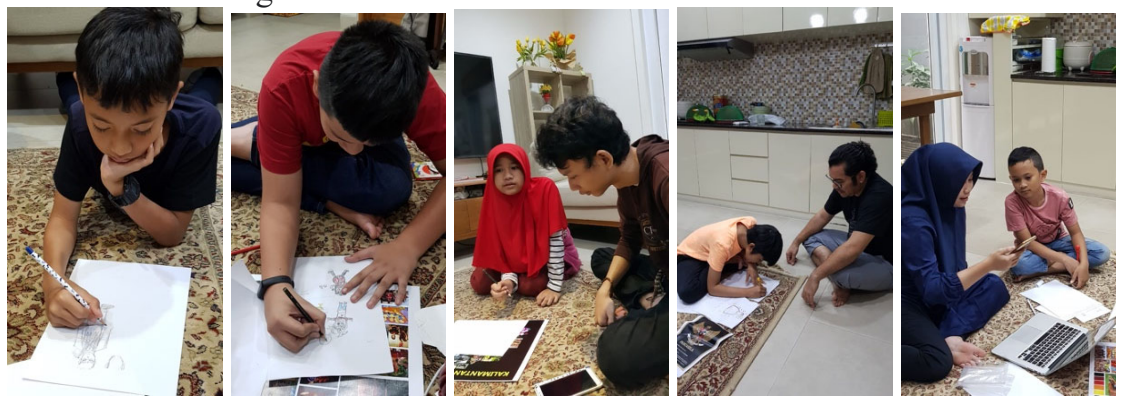

Figure 1. Experimentation

The output derived from the fifth physical experiment are characters manifested in visual images that constitute the self-representation of each member of the experimental group who has shown significant imagination and creativity. Unlike the previous experiments, where the instructions were given by the researcher, in the fifth physical experiment the members of the experimental groups were given the freedom to develop fairy tale narratives and visual image characters. The role of facilitator assigned to each of the experimental groups was also significant in directing them to keep their imagination and creativity stay in the set boundaries. Each member of the experimental group created a folktale narrative along with a character who represents him/herself, each accompanied by a research team personnel.

The analysis of the results of Experiment 5 is as follows:

Using the character approach through the mood board, Subject 1 (Adit) created two characters called Toni and Banu. Toni acts the main character and Banu is Toni's friend. The narrative tells the life, abode, religion, nature, and habits of Toni and Banu as written by Adit in a flow of thought illustrated in the following picture:

Figure 2. Mind Flow from Subject 1 (Adit)

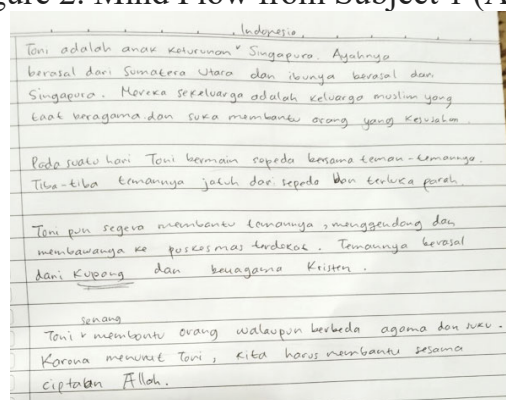

The researchers provided facilitation to obtain a more thorough exploration of Toni and Banu characters. After approximately 30 minutes, the physical attributes, hobbies, habits and age of e Toni and Banu where established. Choosing the Maluku tribe as cultural background, a mood board was prepared in the form of traditional houses, decorations, traditional clothes, physical appearance of the Moluccans, and other characteristics. The Mood board played a large role in influencing Subject 1 in creating the visual image of his characters

Subject 1 related his daily activities in the narrative and visual image characters he created Both of the characters exhibit a passion that is similar to the narrator, namely cooking. The selected accessories resemble the current fashion trend of the digital native generation. The main focus of Subject 1 was on the two characters, without any real attention being paid to the backgrounds such as the environment. The first character that was 
created was a man named Toni who was of a Singaporean and North Sumatran decent, after which Subject 1 created a character named Banu who is of a Mollucan ethnicity.

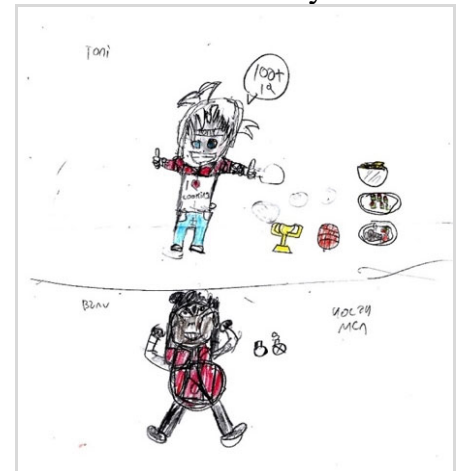

Figure 3. Visual Images from Subject 1

Further, the authors collected field data through experiments. The experiments conducted included observing the response of the digital native generation to media other than the digital media. The authors formed an experimental group of 15 people who were randomly drawn from respondents. The experiment was carried out in 2 stages with different media approaches. In the first stage, the media used is card games media and board games as conventional media. Whereas in the second stage, the media used is a mixture of conventional media and digital media, namely picture books with augmented reality elements.

The analysis of the results of experiment on Subject 1 shows that he is able to describe the kind of character as he wants it be from the appearance, traits/nature, hobbies, to the character's relationship with the environment. As such, Subject 1 is considered to be able to represent himself in a visual imagery by means of the two characters who have their own respective strong characteristics, displaying a gleeful facial expression and a fairly dynamic attitude. The phrasing used by Subject 1 makes it possible to make visual images from narratives based on the characters he has made.

Further the narrative made by Subject 2 (Brina) involves an 11 year old girl named Dirte Arley Kerial, of English blood from her father's side, undergoing fifth grade in a private elementary school, with the following physical characteristics: medium body size with a height of $139 \mathrm{~cm}$, light blue eyes, slightly dark skin, waistlength wavy hair with red at the bottom, bland facial expression, wearing a stirrups, sporting blue glasses, a watch with a picture of white diamond, wearing a white uniform with green stripes on wrist and collar, yellow ribbon, long white skirt, white high neck converse shoes with Tosca color stripe, wearing casual attire using a violet hoodie jacket, light brown jeans, red hairclips, carrying modern white rather small sling bag with blue striped. She has black wings, rather large, passed down from his mother. The character created by Subject 2 live in a world where everyone has special abilities, and what this specific characters has are wings that are passed down from her mother

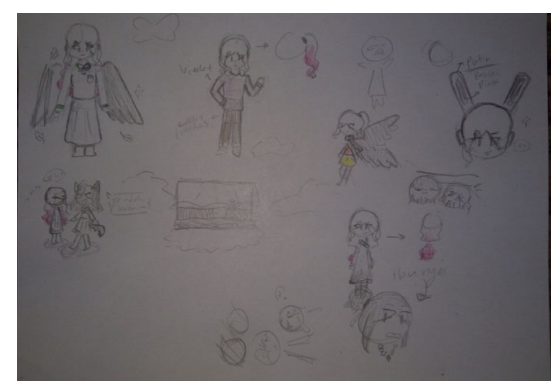

Figure 4. Visual Images from Subject 2

The character is an introvert, among the top four 4 in her school. Her hobbies are studying, reading comics such as comedy, fantasy, and drama, handicrafts (making pencil \& plushie holder). She was born on October 31, under the zodiac sign Scorpio, has a younger twin brother with whom she is close. Her favorite food is pizza, and her favorite drink is cocoa. Her favorite color is red. She likes rabbits. She is a bit sloppy, but responsible, lazy to move around, wealthy, has few friends, has a room with pastel purple walls, tidy when someone visits (usually messy). In her room there are lots of threads for crafting, books, a laptop, and an alarms clock. She is choosy when it comes to friends. She is close with her father, not so close with her mother. She likes to fly at night, see the stars. There is a platform in the sky (behind the clouds) which serves as her hideout. Usually she would go there when she had a fight with her mother. She, likes ballads but sometimes would listen to pop / uplifting music when she is happy. She usually listens to music while crafting, using a pair of head phone that has rabbit ears on it. What she dislikes are her mother, morning mother, social activities, neon colors, noise, crowds. She is able to speak English, understands Japanese and Korean (but cannot speak them well). She likes to fly around 
house with his father. She is often sick, and is left hand dominant.

A very detailed description of the character is then transformed into a visual image. The analysis of the results of experiment 5 on Subject 2 finds that he is very capable of describing what kind of character he wants to make, from appearance, nature, hobbies, to the character's relationship with his/her(?) environment which is a representation of himself (himself). The visual images method description of Subject 2 depicts the character various attitudes, starting with standing up straight, walking, interacting, and carrying various facial expressions such as smiling, confused, and sullen. Attributes are given such as wings and trendy teen girl costumes. The way by which the image created by Subject 2 makes it possible to make a wimba narrative of the form image, which is of a preadolescent girl with special abilities and strengths to carry out a mission. Strong characteristics were given to the of the character created by Subject 2 .

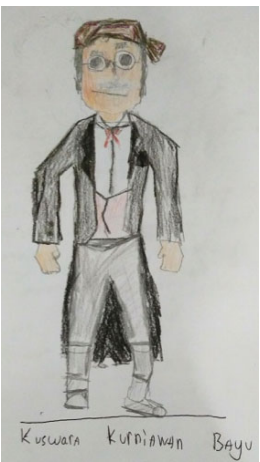

Figure 5. Visual Images from Subject 3

Narrative relating to the characters created by subject 3 (Kei) is as follows: Character Name is Kuswira Kurniawan Bayu. Kuswira means leader. Kurniawan means a gift of God and Bayu is the wind. The character is humorous, fair, honest, religious, tolerant, and always helpful. His physical attributes include curly hair, normal weight, big eyes, sharp nose, clean teeth and thin mustaches. His hobbies includes drawing, hiking, traveling, and studying history. He likes playing traditional and orchestral musical instruments. He is good at martial arts of pencak silat. This character is narrated as having been born in Banten, descended from the royal family of Tarumanegara, but follows a simple philosophy in life.

The experiment met with some problems as Subject 3 got carried away in building character based on what he liked, and thus he forgot the concept had earlier been made. Analysis of the result of Experiment 5 on Subject 3 shows that the subject is quite capable of describing what kind of character he wants to make, starting from appearance, nature, hobbies, to the character's relationship with the environment. However, the subject was not focused due to his desire to create different characters at the same time, leading to inconsistency. Description of various visual images created by Subject 3 is a character standing straight made to represent his own attributes. The character bears a friendly expression with a smile and his large eyes and sports a number of accessories, such as glasses, blankon (traditional headwear), and wearing and European-style suit. The description of the image created by Subject 3 makes it possible to build a visual images from narratives of a character who mixes western and eastern cultures and possesses very strong characteristics.

The next narrative was made by Subject 4 (Evin) who made a character that represented the 3rdvalue of Pancasila. The character is a descendant of the King of Jambi. The narrative made by the fourth subject is as follows: a 17 year old young man whose birthday is on January 1, has martial arts skills. His hobbies are playing football, playing games, watching movies, especially of the superhero genre. This character has super physical strength, bone of steel, but has a weakness in the form of cold temperatures. His favorite color is black and he really likes anything having to do with technology. Things that he dislikes are snacking, animals, and his family. He's kind, brave, happy to help people, but a bit ignorant, and does not like formal studies. The character's physical characteristics include: short, straight, brownish black hair, brown eyes, brown skin, and a muscular physique. He loves to wear plain navy blue t-shirts, training pants, and black Nike sneakers. The character also carries weapons in the form of a bazooka and multipurpose gloves. He lives in a bunker, under the city, and Alone without a family. 


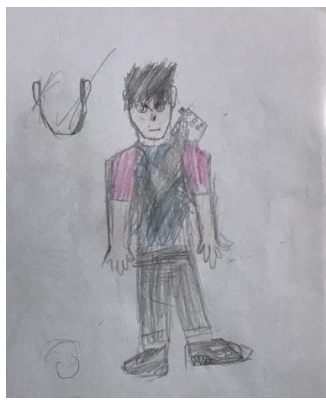

Figure 6. Visual Images from Subject 4

Analysis of the experiment results shows that initially the subject had difficulty in coming up with narratives and characters. The mood board approach was quite helpful in stimulating the fourth subject to imagine what kind of character he wants to make, starting from appearance, nature, hobbies, to the character's relationship with the environment. However, after finding the rhythm, the Subject 4 was swept up in the process of bringing his character to life with his imagination tending towards the dark but with some bright features. It presents a paradox.

The results of the experiment on Subject 4 was marked by a visual images description that depicted a strapping man standing upright gazing straight ahead and glaring. The face features an aerious facial expression without a smile. Attributes worn include a weapon and a teenage boy's everyday apparel, of a t-shirt and trousers. The expressiveness of the work of Subject 4 makes it possible to create visual image narratives of a character made with strong characteristics.

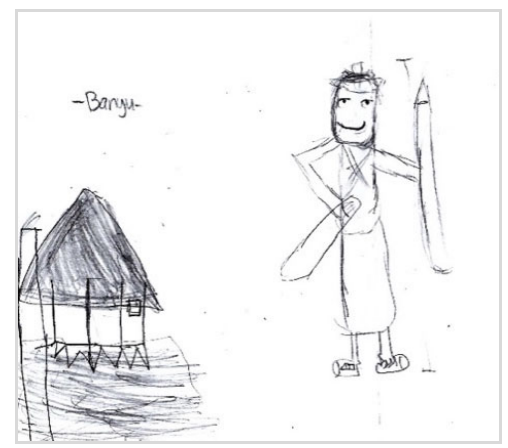

Figure 7. Visual Images from Subject 5

Subject 5 (Banyu) appears to be a little different from the other subjects. While other subjects started off by creating human characters, this was not the case with the fifth subject. He chose to create a visualization of a traditional house, followed by a weapon in the form of a spear, and only then did he introduced a human object. The unwritten narrative makes the subject appear to be repeating what was on the mood board.

From analysis of the experiment results, the subject did not appear to be enthusiastic in making the narrative and character. He seemed to only have enjoyed the mood board that had been prepared and redrawing it. This made it difficult for researchers to make analysis as the image does not represent what was on the subject's imagination. Description of the various visual image presents a male figure standing upright carrying a weapon with a smiling face. Description of the creation of Subject 5 allows for a visual images from narratives based on traditional houses and strong feature of the character.

\section{Conclusion}

The research subjects represent the digital native generation. The narratives of the stories produced by the five research subjects varied according to their references, hobbies and preferences. Most of them linked the visual characters to their daily activities. The resulting visual image is a representation of themselves.

\section{References}

Baudrillard, Jean. (1983). Simulations. Semiotext[e].

Creswell, John W. (2009). Research Design.California: SAGE.

Elkins, James. (2003). Visual Studies, Great Britain: Routledge

Mannheim, Karl (1952). "The Problem of Generations". In Kecskemeti, Paul (ed.). Essays on the Sociology of Knowledge: Collected Works, Volume 5. New York: Routledge. p. 276-322

Melonio, Alessandra., Gennari, Rossela. Co-Design with Children: The State of Art. Italy: KRBD Research Centre for Knowledge and Data. University of Bozen

Prensky, Marc (October 2001). "Digital Natives, Digital Immigrants". On the Horizon. 9 (5): 1-6. MCB 
University Press

Shin, Y.J. (2016). Educating Children in the Digital Age. Mizan, Jakarta

Stillman, D \& Stillman, J. (2017). Generasi Z. PT.Gramedia Pustaka Utama, Jakarta

Strauss, W \& Howe, N. (1991). Generation. William Morrow \& Company, Inc., New York 